AUTORA:

Mychely Fernandes RêGo

ORIENTADOR:

Afonso Celso Pinto Nazário

CO-ORIENTADORA:

Maria Aluca de la luz Huidobro Navarrete

Resumo de tese

Palavras-chave

Fibroadenoma Mama

Antígeno Ki-67

Ciclo celular

Ciclo menstrual

AUTORA:

Patrícia Gonçalves Teixeira

ORIENTADOR:

Prof. Dr. Cezar Alencar de Lima Rezende

Resumo de tese

Palavras-chave

Angiogênese

Pré-eclâmpsia

Fator de crescimento endotelial vascular (VEGF)

Fator de crescimento placentário (PIGF)
Análise imuno-histoquímica do fibroadenoma mamário humano por meio do antígeno de proliferação celular ki-67 durante as fases folicular e lútea do ciclo menstrual

Immunobistochemical analysis of human mammary fibroadenoma by cell

proliferation antigen ki-67 during the follicular and luteal phases of menstrual cycle

Tese apresentada ao Departamento de Ginecologia da Universidade Federal de São Paulo - Escola Paulista de Medicina, para obtenção do título de Doutor em Ciências, em 22 de junho de 2006.

OBJETIVO: comparar por meio da expressão do antígeno Ki-67 a atividade proliferativa do epitélio do fibroadenoma mamário nas fases folicular e lútea do ciclo menstrual.

MÉTODOS: Foram selecionadas 90 mulheres eumenorréicas, sem uso de terapia hormonal, que apresentavam nódulos mamários benignos, divididas em dois grupos, de acordo com a fase do ciclo menstrual em que se encontravam no dia do procedimento cirúrgico para exérese do tumor. Ao final do estudo foram avaliadas 75 pacientes, portadoras de 87 nódulos. Analisou-se então a expressão epitelial do antígeno Ki-67 nos fibroadenomas sem conhecimento prévio de qual grupo pertenciam, com leitura em duplicata.

RESULTADOS: os grupos mostraram-se homogêneos em relação à idade, à menarca, ao índice de massa corpórea, à história de gestação anterior, à paridade, à amamentação, ao número de fibroadenomas e aos antecedentes familiares de câncer de mama e tabagismo. $\bigcirc$ tamanho médio do tumor foi de $2,0 \mathrm{~cm}$, não havendo relação entre a atividade proliferativa e o seu diâmetro. Não se obteve padrão de comportamento na expressão do Ki-67 em tumores distintos numa mesma paciente. A média da expressão do Ki-67 por mil células epiteliais contadas no grupo 1 (fase folicular) foi de 27,8 e no grupo 2 (fase lútea) de 37,8 ( $p=0,116)$.

CONCLUSÃO: a atividade proliferativa do epitélio do fibroadenoma mamário não se mostrou diferença significante nas fases folicular e lútea do ciclo menstrual.

\section{Fatores de angiogênese na pré-eclâmpsia e a correlação com os níveis da pressão arterial média}

Angiogenic factor in preelampsia and the correlation with mean arterial pressure

Dissertação de Mestrado apresentada ao Programa de Pós-Graduação em Saúde da Mulher da Faculdade de Medicina da Universidade Federal de Minas Gerais, em 22 de dezembro de 2006.

OBJETIVO: avaliar os níveis plasmáticos do fator de crescimento endotelial vascular (VEGF) e fator de crescimento placentário (PIGF) em gestantes com e sem pré-eclâmpsia e correlacionar com a pressão arterial média (PAM).

MÉTODOS: estudo transversal, tipo caso-controle, com 23 gestantes com pré-eclâmpsia e nove normotensas admitidas na Maternidade do Hospital das Clínicas da UFMG (outubro de 2004 a janeiro 2006). A concentração plasmática de VEGF e PIGF foi determinada pelo método de ELISA (Kits R \& D Systems). Os valores médios das concentrações plasmáticas do VEGF e PIGF foram comparados entre os grupos (Student-ł teste). As correlações entre os valores da PAM e os níveis plasmáticos de VEGF e PIGF foram avaliadas através da análise de regressão.

RESULTADOS: a concentração plasmática de PIGF estava significativamente diminuída nas pacientes com pré-eclâmpsia em relação às normotensas $(40,8 \pm 37,5 \mathrm{pg} / \mathrm{ml}, 480 \pm 347 \mathrm{pg} / \mathrm{ml}$, média $\pm \mathrm{DP}, \mathrm{p}=0,005)$. Houve também correlação inversa entre os níveis plasmáticos de PIGF e a PAM. Para cada diminuição de lpg/ml na concentração de PIGF, houve aumento de 6,5 mmHg na PAM ( $p=0,002)$. As concentrações plasmáticas do VEGF não se mostraram estatísticamente diferentes nos dois grupos $(243,3 \pm 193 \mathrm{pg} / \mathrm{ml}, 160,6 \pm 143 \mathrm{pg} / \mathrm{ml}$, média \pm DP, p= 0,238) nem houve correlação com a PAM.

CONCLUSÃO: estes resultados mostram que o PIGF pode exercer papel determinante na pressão arterial média em gestantes com pré-eclâmpsia. 